\title{
Erratum to: Urban policy in Asia Pacific countries: a case for inclusionary zoning and housing
}

\author{
Alok Kumar Mishra ${ }^{1}$ Prasanna Kumar Mohanty ${ }^{1}$
}

Published online: 28 April 2017

(C) The Japan Section of the Regional Science Association International 2017

\section{Erratum to: Asia-Pac J Reg Sci \\ DOI 10.1007/s41685-017-0026-4}

Inadvertently, Fig. 1 below was not included in the original publication of the article.

The original article has been corrected.
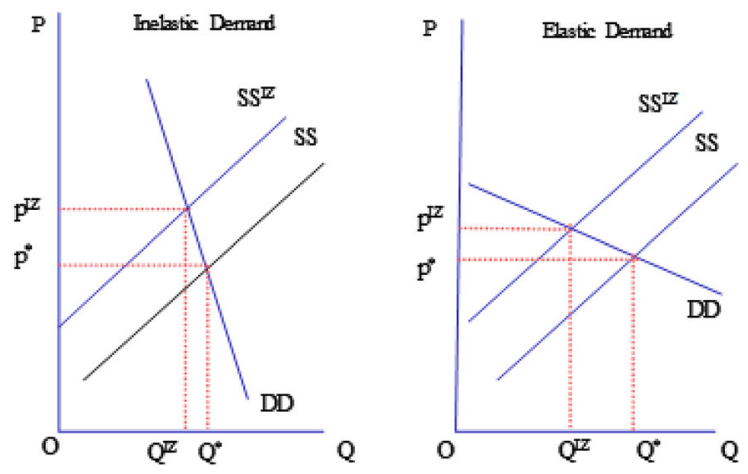

Fig. 1 Effect of inclusionary zoning: inelastic and elastic demands for housing

The online version of the original article can be found under doi:10.1007/s41685-017-0026-4.

Alok Kumar Mishra

misalok@gmail.com

1 School of Economics, University of Hyderabad, Hyderabad, Telangana, India 